these reports, we found no evidence that the growth in children with frequent generalised tonic-clonic seizures was impaired relative to those who had infrequent partial seizures.

Phenytoin, phenobarbitone, carbamazepine, and valproate increase the metabolism of sex hormones and enhance the synthesis of sex hormone binding globulin in the liver. ${ }^{2}$ In boys the increase in sex hormone binding globulin leads to an increase in total testosterone concentration, but the concentration of the free fraction remains unaltered. ${ }^{2}$ In adult women increases in serum growth hormone have been noted during treatment with carbamazepine and phenytoin, but the rise in growth hormone caused by insulin hypoglycaemia may be less than expected in adults on antiepileptic drugs. ${ }^{2}$ Comparable data are not available for children. It has been postulated that short stature, which has been reported in adult men with epilepsy, ${ }^{6}$ might be consequent on the use of phenytoin in childhood, but our evidence suggests that antiepileptic drugs do not have clinically important effects on height attainment up to puberty.
The helpful advice from Professor MA Preece for the analysis of the growth data is gratefully acknowledged.

\section{References}

1 Meldrum BS, McWilliam JR. Hormone changes following seizures. In: Dam M. Gram L. Pewry JK. Advances in epileptology: XIIth Epilepsy International Symposium. New York: Raven Press, 1981:441-8.

2 Fichsel H. Hormonal changes in children receiving antiepileptic drugs. In: Dam M. Gram L. Pewry JK. Advances in epileptology: XIIth Epilepsy International Symposium. New York: Raven Press, 1981:449-59.

${ }^{3}$ Round JM. Growth, development and biochemical changes during puberty in a population of epileptic children. In: Dam M. Gram L. Pewry JK. Advances in epileptology: XIIth Epilepsy International Symposium. New York: Raven Press, 1981:461-7.

4 Tanner JM. Notes on the reporting of growth data. Hum Biol 1951:23:93-159.

5 Tanner JM. Gupta D. A longitudinal study of the urinary excretion of individual steroids in children from 8 to 12 years old. Journal of Endocrinology 1968:41:139-56.

"McGowan MEL. Final adult height of patients with epilepsy. Dev Med Child Neurol 1983;25:591-4.

Correspondence to Dr S J Wallace, Department of Paediatrics, University Hospital of Wales, Heath Park, Cardiff CF4 4XW, Wales

Received 1 August 1986

\title{
Preoperative stabilisation in congenital diaphragmatic hernia
}

\author{
P H T CARTLIDGE, N P MANN, AND L KAPILA \\ Department of Neonatal Medicine and Surgery, City Hospital, Nottingham
}

SUMmaRY Critically ill infants with congenital diaphragmatic hernia were treated by either early surgery or delayed surgery after preoperative stabilisation. The preoperative stabilisation was aimed at correcting acidosis and hypoxia, thereby reducing the severity of persistent fetal circulation. Survival improved from $12.5 \%$ after early surgery to $52.9 \%$ after delayed surgery.

Infants with congenital diaphragmatic hernia often have severe acidosis and hypoxia at presentation. Immediate repair may lead to an improvement, but many infants deteriorate with increasing hypoxia, dying after a 'honeymoon period' of about 18 hours. This deterioration is usually due to persistent fetal circulation, which is a consequence of hypoxia, acidosis, and the innately abnormal pulmonary arterioles, which are more muscular and reduced in number. ${ }^{12}$ Recent reports have suggested that preoperative treatment aimed at correcting acidosis, hypoxia, and tissue hypoperfusion decreases the severity of persistent fetal circulation and improves survival. $^{3-5}$ In 1983 we adopted this new management approach. This paper reports our results.

\section{Patients and methods}

From January 1981 to November 1985, 33 infants with congenital diaphragmatic hernia presenting within two hours of birth were treated in our department; their details are shown in Table 1.

Before August 1983, 16 infants were treated with early surgery. Preoperatively most were ventilated only briefly while surgery was organised. Stomach aspiration was used to decompress the bowel. Metabolic acidosis was treated with sodium bicarbonate.

After August 1983, 17 infants were treated with delayed surgery after a period of preoperative stabilisation. Infants in respiratory failure were paralysed with tubocurare and ventilated using low pressures and high rates. Stomach aspiration was again performed. Arterial and venous catheters were inserted through the umbilical vessels. The 
Table 1 Details of infants with congenital diaphragmatic hernia presenting within two hours of delivery

\begin{tabular}{|c|c|c|}
\hline & \multicolumn{2}{|l|}{ Surgery } \\
\hline & $\begin{array}{l}\text { Early } \\
(n=16)\end{array}$ & $\begin{array}{l}\text { Delayed } \\
(n=17)\end{array}$ \\
\hline \multicolumn{3}{|l|}{ Gestation (weeks): } \\
\hline Mean (SD) & $38.9(2 \cdot 4)$ & $37 \cdot 5(2 \cdot 6)$ \\
\hline Range & $31-42$ & $32-40$ \\
\hline \multicolumn{3}{|l|}{ Birth weight $(g)$ : } \\
\hline Mean (SD)* & $3170(630)$ & $2690(680)$ \\
\hline Range & $17(0)-4140$ & $1750-3670$ \\
\hline Female:male & $8: 8$ & $6: 11$ \\
\hline Inborn:outborn & $6: 10$ & $9: 8$ \\
\hline Left:right hernia & $15: 1$ & $13: 4$ \\
\hline Mean (SD) Apgar score at one minute & $4(1 \cdot 7)$ & $3.9(1.9)$ \\
\hline Congenital heart disease & 2 & 3 \\
\hline Prematurity & 1 & 5 \\
\hline
\end{tabular}

${ }^{*} \mathrm{p}<0 \cdot 05$.

partial pressure of oxygen in post-ductal blood was monitored using the arterial catheter (Searle) and in pre-ductal blood using a transcutaneous oxygen electrode. If hypoxia could not be corrected by ventilation tolazoline $(1-2 \mathrm{mg} / \mathrm{kg} / \mathrm{h})$ was given. Circulatory failure was treated with plasma and dopamine $(2-10 \mathrm{mcg} / \mathrm{kg} / \mathrm{min})$ and metabolic acidosis with sodium bicarbonate. The stabilisation procedure lasted four to 16 hours and the infant proceeded to surgery when his condition was considered optimum.

At operation the diaphragm was usually sutured directly, but if the defect was too large a prosthetic graft was used. If the abdominal wound could not be closed a similar graft was inserted. An ipsilateral chest drain with an underwater seal was used without suction.

Postoperatively, all infants received ventilation, dopamine, tolazoline, and sodium bicarbonate, as necessary. Central venous pressure monitoring in the group who received delayed surgery allowed for more accurate fluid management. In particular, plasma was used more liberally to replace losses from the wound. Paralysis was stopped when an improvement in ventilation was seen, which was usually after several days.

Statistical analysis was by Student's unpaired $t$ test and $\chi^{2}$ analysis with Yates's correction.

\section{Results}

Details of treatment and outcome are summarised in Table 2. The preoperative $\mathrm{pH}$ was significantly better in the group who received delayed surgery $(\mathrm{p}<0.001)$, and all infants with a preoperative $\mathrm{pH}<7.2$ died. The prevalence of contralateral pneumothorax decreased from six after early surgery to one after delayed surgery; all seven infants died. Survival improved from $12.5 \%$ after early surgery to $52.9 \%$ after delayed surgery $(p<0.05)$. Five infants had congenital heart disease and they all died. When these five infants were excluded survival rates were $14.3 \%$ after early surgery and $64.3 \%$ after delayed surgery $(p<0.05)$. Ventilation from birth was required in 22 infants; all 10 in the group who received early surgery died, whereas four of the 12 in the group who received delayed surgery survived, two of them despite being profoundly acidotic with a $\mathrm{pH}$ of 6.85 and 6.98 shortly after birth.

\section{Discussion}

This study suggests that a period of treatment aimed at correcting acidosis, hypoxia, and hypoperfusion preoperatively is associated with improved survival of critically ill infants with congenital diaphragmatic hernia. Ventilation was most effective and the prevalence of pneumothoraces lower if the infant was paralysed and a rate of roughly 60 breaths per minute used. The infants usually improved considerably after several hours of efficient ventilation, and some required no other preoperative treatment. Other infants had metabolic acidosis due to low cardiac output and tissue hypoperfusion. This could usually be corrected preoperatively by giving plasma and sodium bicarbonate, but it often recurred

Table 2 Treatment and outcome in infants presenting with congenital diaphragmatic hernia within two hours of delivery

\begin{tabular}{lll}
\hline & Surgery & \\
\cline { 2 - 3 } & $\begin{array}{l}\text { Early } \\
(n=16)\end{array}$ & $\begin{array}{l}\text { Delayed } \\
(n=17)\end{array}$ \\
\hline $\begin{array}{l}\text { Preoperative treatment: } \\
\text { Ventilation }\end{array}$ & 14 & 17 \\
Dopamine & 1 & 2 \\
Tolazoline & 0 & 4 \\
Paralysis & 0 & 11 \\
Plasma & 2 & 7 \\
Sodium bicarbonate & 10 & 11 \\
Highest preoperative pH $+:$ & & $7 \cdot 30(0 \cdot 11)$ \\
Mean (SD)* & $7 \cdot 04(0 \cdot 21)$ & $7 \cdot 14-7 \cdot 47$ \\
Range & $6 \cdot 77-7 \cdot 45$ & 16 \\
Postoperative treatment: & 13 & $(1$ died before \\
Ventilation & $(1$ died during & operation $)$ \\
& 10 & 10 \\
Dopamine & 10 & 12 \\
Tolazoline & 2 & 16 \\
Paralysis & 2 & 9 \\
Survivors:** & & \\
\hline
\end{tabular}

${ }^{*} \mathrm{p}<0 \cdot 001$ By Student's $t$ test.

${ }^{* *} \mathrm{p}<0.05 \mathrm{By} \chi^{2}$ test with Yates's correction.

†Arterial pH. 
during the operation. Infants with left sided diaphragmatic hernia often have a mild degree of left ventricular hypoplasia. ${ }^{6}$ Their cardiac output is likely to be reduced, so it is not surprising that surgery is poorly tolerated. These infants could probably be helped by the use of dopamine started preoperatively, as used by Nair et al..$^{3}$

There was a coincidental increase in the use of abdominal wall grafts in infants treated by delayed surgery. It was our impression that their use benefited a few infants by facilitating ventilation. From autopsy evidence, however, we consider that only one infant not so treated would have benefited from a graft. It is therefore very unlikely that the improved survival was the result of the increased use of grafts.

We recommend that critically ill infants with congenital diaphragmatic hernia who present shortly after birth are stabilised before operation. If with this treatment the acidosis persists, with a $\mathrm{pH}<7 \cdot 20$, it is very unlikely that surgery will help.

We thank Miss M J Mayell for allowing us to study patients under her care, Dr S J Bodden, who was instrumental in devising the new protocol, and Mrs F Prew for typing the manuscript.

\section{References}

${ }^{1}$ Levin DL. Morphologic analysis of the pulmonary vascular bed in congenital left-sided diaphragmatic hernia. $J$ Pediatr 1978;92:805-9.

2 Geggel RL, Murphy JD, Langleben D, et al. Congenital diaphragmatic hernia: arterial structural changes and persistent pulmonary hypertension after surgical repair. J Pediatr Surg 1985;107:457-63.

${ }^{3}$ Nair UR, Entress A, Walker DR. Management of neonatal posterolateral diaphragmatic hernia. Thorax 1983;38:254-7.

${ }^{4}$ Manthei U, Vaucher Y, Crowe CP. Congenital diaphragmatic hernia: immediate pre-operative and post-operative oxygen gradients identify patients requiring prolonged respiratory support. Surgery 1983;93:83-7.

5 Reynolds M, Luck SR, Lapper R. The 'critical' neonate with diaphragmatic hernia: a 21 -year perspective. J Pediatr Surg 1984;19:364-9.

6 Siebert JR, Haas JE, Beckwith JB. Left ventricular hypoplasia in congenital diaphragmatic hernia. J Pediatr Surg 1984;19: $567-71$.

Correspondence to Dr P H T Cartlidge, Department of Neonatal Medicine and Surgery, City Hospital, Hucknall Road, Nottingham NG5 1PB. England.

Received 9 June 1986

\title{
Neonatal typhoid fever
}

\author{
K C CHIN, E J SIMMONDS, AND M J TARLOW
}

University of Birmingham, Department of Paediatrics and Child Health, East Birmingham Hospital

SUMmary Three infants of Pakistani immigrant mothers developed typhoid fever in the neonatal period. All three survived, but two became chronic excretors of Salmonella typhi. The risk of an outbreak of typhoid fever in a maternity unit or special care baby unit is emphasised.

Typhoid fever is rare in neonates. ${ }^{12}$ The public health problems it poses, however, are great. This report describes three neonates with typhoid fever born in two maternity hospitals in Birmingham over the past nine years.

\section{Case reports}

Case 1. After a normal birth and 24 hour discharge from Marston Green Hospital, Birmingham, a full term Pakistani girl presented at this hospital, very ill, shocked, and hypothermic at the age of 3 days. She had a 12 hour history of increasing lethargy and poor feeding.
After admission, she had a cardiorespiratory arrest and subsequently needed assisted ventilation for 48 hours because of attacks of apnoea. She also had episodes of clonic seizures and hypoglycaemia. A chest radiograph showed bilateral patchy consolidation. The blood culture grew Salmonella typhi phage type $E_{1}$ after incubation for three days. Results of lumbar puncture were normal. Repeated stool and urine cultures yielded negative results. Treatment with antibiotics was changed from ampicillin and gentamicin to trimethoprim when the results of the culture were known. Trimethoprim was given for two weeks, during which time she had neither fever nor diarrhoea. At 6 months the infant has microcephaly and neurodevelopmental delay. Multiple stool cultures from the mother and her family have remained negative for $S$. typhi. No cross infection occurred while the baby was nursed in the intensive care unit where a strict hand washing policy was operated, although the baby was not isolated.

Case 2. After three days of intermittent fever a 